\title{
Analysis on Permanent Magnet Synchronous Motor and Its controller for Electric Vehicle
}

\author{
Liu Shuhua ${ }^{1}$, Liu Kunlun ${ }^{2}$, Zhang Xingguo ${ }^{1}$ \\ ${ }^{1}$ Nanchang Institute of Science and Technology, Nanchang China, 330108 \\ ${ }^{2}$ Zhengzhou University, Henan China, 450001
}

Keywords: electric vehicle; motor; permanent magnet synchronous; controller

\begin{abstract}
The research and development of electric vehicles has become more and more common. This paper, according to the operating characteristics of electric vehicles motor, offers corresponding control strategies. Through experiments, the overall system of prototypes is excellent and can meet the needs of electric vehicle driving.

At present, the petrochemical industry is increasingly polluting the environment in China, and people are starting to pay attention to it. Under such an industry background, electric vehicles have come into notice of people, which are different from traditional oil-fueled vehicles. Traditional oil-fueled vehicles will cause a lot of exhaust emissions, which cause great pollution to the surrounding environment and endanger people's health. The emergence of electric vehicles has effectively solved this problem, which will not cause the exhaust gas pollution and effectively solve this technical problem. The electric drive system is the key point for the development of electric vehicles. Various types of electric motors and matched controllers are can be applied in electric vehicles to operate, in order to achieve the ideal operation. permanent magnet synchronous motors have high efficiency and high control precision, has a more ideal effect in the actual application, combined with power electronics and advanced control technology, so it has a high value in the application of electric vehicle drive.
\end{abstract}

\section{Development situation and classification of drive motor for electric vehicle}

At present, the automobile industry in China is developing rapidly and the requirements of people for automobile are increasingly higher. In the case of limited capacity and performance of the on-board power supply, the source of electric vehicle power mainly depends on the dynamic performance and the vehicle's own battery performance, which are determined by the drive motor. In general, there are the following requirements for the performance of the drive motor: reliability, adaptability, small size, light weight, high efficiency, and so on. In the process of actual application, these aspects should all be well represented. The motors that are commonly used in electric vehicles include: Direct-current motor, switched reluctance motor, asynchronous motor, and permanent magnet synchronous motor. These motors perform well in practical application ${ }^{[2]}$.

\subsection{Direct-current motor}

DC motor is applied in our country relatively early because of its relatively strong bearing capacity, once widely used. And DC motor has large starting and braking torques, superior speed control performance, simple control schemes and low requirements of personnel, and it is the most common electric motor at early times. However, with the continuous development of the times and the continuous advancement of science, people have found that DC motors have certain deficiencies in the practical application. When DC motors are used in high-power operation, they will generate certain sparks, which will have a certain impact both on the automobiles and the safety of drivers.

\section{2 switched reluctance motor}

Switched reluctance motor is a kind of motor purely relying on the asymmetry of magnetic 
circuit to make it produce reluctance torque. The advantage of this type of motor is that its structure is very strong, not easy to be destroyed by external force, and the manufacturing cost is very low, and the efficiency of operation is high. By virtue of these advantages, the switched reluctance motor was also popular, however, the disadvantage is that there is a certain degree of pulsation in the output torque, will produce a lot of noise in operation, and sometimes even affect the driving and the comfort of the ride ${ }^{[3]}$.

\section{3 asynchronous motor}

The main feature of asynchronous motors is that its structure is relatively simple and durable. In particular, there is not problem of commutator for the squirrel-cage asynchronous motors studied later, and the manufacturing costs are relatively low, ideal for high-power application. At the same time, induction motors also have certain shortcomings. The operating system of asynchronous motors is complex and the driving cost is high. At present, there are still a few automobile manufacturers in China that use asynchronous motors.

\subsection{Permanent magnet synchronous motor}

The emergence of the permanent magnet synchronous motor is relatively late, compared with the asynchronous motor, therefore, the energy-saving effect of synchronous motor is more obvious, and it is even more suitably used in vehicles with limited vehicle battery capacity. The interior permanent magnet motor in permanent magnet synchronous motor has been found that it has a series of advantages such as high power density, high efficiency, good reliability, small size, and light weight after a long period of practice, and have broad application prospects in the automobile industry today.

\section{Classifications of permanent magnet synchronous motor (see Figure 1)}

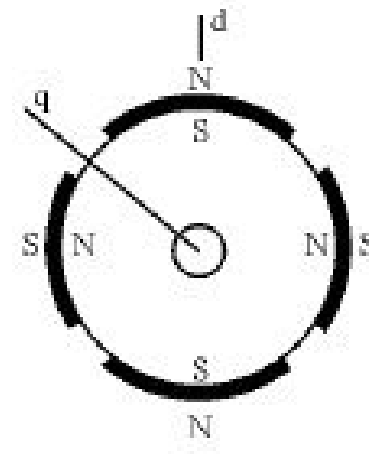

(a)

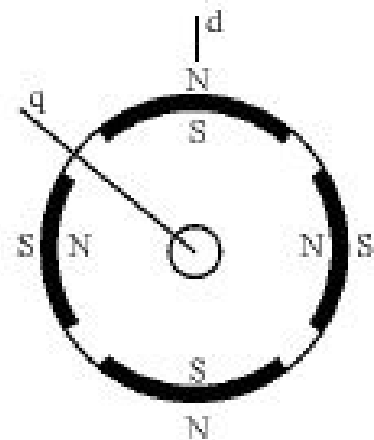

(b)

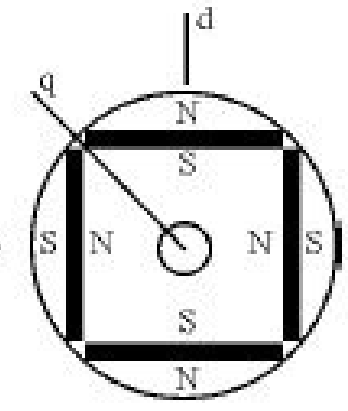

(c)

Figure 1 (a) Surface-mount permanent magnet synchronous motor (b) Embedded permanent magnet synchronous motor (c) Interior permanent magnet synchronous motor

At present, there are many types of permanent magnet motor used in the Chinese market, but the operating principles of all permanent magnet motors are the same, mainly based on the different magnetic circuit structure of the rotor. permanent magnet synchronous motors can be roughly divided into three types, including surface-mount, embedded and interior permanent magnet synchronous motors, and all these three performed ideally in actual application. Surface-mount rotor structure is that permanent magnet is mounted in the external surface of rotor, embedded structure is in the internal side of rotor, and interior structure is in the interior of iron core of the rotor and surrounded by it.

\subsection{Surface-mount permanent magnet synchronous motor}

The rotor path of the surface-mount permanent magnet synchronous motor is symmetrical, so the 
diameter can be made small, and the period is more stable during the operation. The rotational inertia and armature inductance of surface-mount permanent magnet synchronous motor are relatively low, which is beneficial to improve the overall operating environment of the system, and the structure of this rotor is relatively simple, the manufacture is also more convenient, and the cost is lower, and it is widely applied in Brushless DC motors and permanent magnet synchronous motors that only operate in a constant torque state.

\subsection{Embedded permanent magnet synchronous motor}

Embedded permanent magnet synchronous motor mainly uses the asymmetry of the rotor to work. In operation, the reluctance torque can increase the output torque of the motor, and it also has a certain flux-weakening capability. Therefore, it is applied in many systems with low requirements for field weakening ${ }^{[5]}$.

\subsection{Interior permanent magnet synchronous motor}

Interior permanent magnet synchronous motor is widely applied in China's current market, and has achieved a more satisfactory application effect. The rotor structure of interior permanent magnet synchronous motor is relatively mechanically strong, and can effectively reduce the risk of the magnet during operation. Because the magnetic circuit cannot be symmetrical, it has a large saliency ratio, in practical application, a large reluctance torque can be generated, a strong field weakening ability can be obtained, and the speed range is very wide. However, the complexity of its structure also leads to a higher manufacturing cost. From the perspective of motor running quality and comprehensive economic efficiency, the use of interior permanent magnet synchronous motor is still a good choice. Permanent magnet material of interior permanent magnet synchronous motor and air magnetic conductor is basically the same, which leads to the reluctance of the A-axis and $\mathrm{D}$-axis motor is similar and the two-axis inductance is almost equal. Interior permanent magnet synchronous motors are the same as those of the embedded permanent magnet synchronous motors and they are all salient-pole synchronous motors. The reluctance of the A-axis and D-axis of the two motors is different, and the inductance between the two is also different. Especially for interior permanent magnet synchronous motors, the existence of salient poles can generate additional reluctance torque when the motor is running, thereby increasing the field weakening performance $^{[6]}$.

\section{Control strategies of electric vehicle driving}

\subsection{Mathematical model of steady-state operation of PMSM}

When the PMSM operates in steady state in the coordinate system, the voltage representation presented by the PMSM is shown in Figure 2:

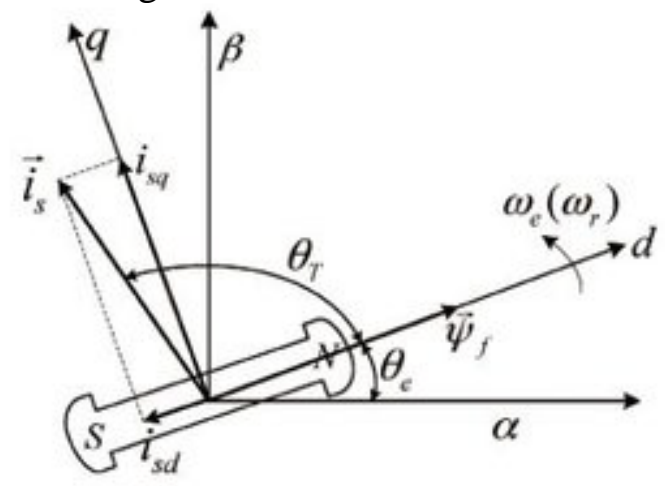

Figure 2

\section{2 current control strategy of electric vehicle}

The features of PMSM for electric vehicle driving is that there is no no-load operation, and in the actual operation, it is required to have strong starting acceleration and low-speed gradeability. From 
the perspective of current overall level of electric vehicles, there is still a considerable gap in speed with traditional oil-fueled vehicles, which is also a technical problem of electric vehicles to be solved at present. First, at different revolving speeds, the drive motors should have different steady-state operating effective load torques. To improve the torque operation, we should consider how to effectively use the reluctance torque of the motor, in order to increase full charge endurance, and it is necessary to increase the efficiency of the electrode.

\section{Control system design of PMSM}

As for permanent magnet synchronous motor speed control systems for electric vehicles with high-performance, it is necessary to have good torque control performance, and a relatively wide range of speed control, in the case of supplying power with the inverter, the prototype can work with magnetic field-oriented vector control ${ }^{[8]}$. The SCM expansion system is an important part of the control system. In order to shorten the cycle of development and operation, thus reducing the cost of operation, and at the same time achieving good driving performance, the high-performance 16-bit microcontroller introduced by Intel Corporation shall be adopted as the core control unit in the this control system. As for the small system other than the SCM, the 8253-type light amplifier is used to detect the output signal during the operation so as to determine the specific position of the motor rotor.

\section{Advantages of permanent magnet synchronous control system (see Figure 3, schematic diagram of permanent magnet synchronous control system)}

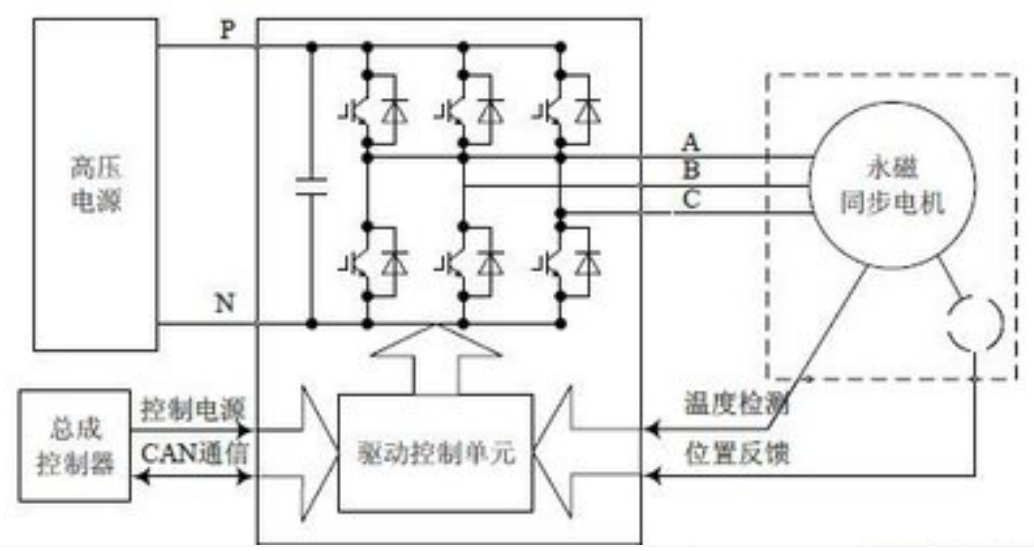

Figure 3

Figure 3 high voltage power supply permanent magnet synchronous motor Assembly control unit control supply CAN communication control unit temperature measurement position feedback with the continuous development of science and technology in our country, expectations of people for the automobile manufacturing industry are also getting greater and higher. With the continuous progress of science and technology in China, more and more in-depth studies have been conducted on the starting and braking of electric motors in electric drives, and many novel development solution shave been proposed. With the continuous progress of the times, the manufacture of synchronous motor control system in our country has reached a new height. permanent magnet synchronous motors have good static and dynamic characteristics, and are more suitable for machine tools, robots and some flexible manufacturing systems. Compared with other control systems, the permanent magnet control system has the following advantages: First, the volume of permanent magnet material with high-performance will be appropriately reduced with the power during the operation; second, if there is not magnetic reluctance, the rotor will conduct copper loss, so the working efficiency would be relatively high; Third, the rotor rotation inertia is small, so the dynamic performance is relatively good; Fourth, the power density is relatively high, generally, $1 \mathrm{kw}$ 
$/ \mathrm{kg}$ can be reached, higher than induction motor ${ }^{[9]}$.

\section{Research situation and development trend of permanent magnet synchronous motor controller}

So far, permanent magnet synchronous motor has been matured in the constant torque region, and main researches focus on the closed-loop control of high performance. In order to improve the performance of the control system, the closed-loop control system uses the magnetic field position information of the rotor position sensor to control rotor current frequency and phase position, etc. Of permanent magnet synchronous electrode in order to determine the relationship between the rotor current, resulting in a constant rotor torque, that is, auto-control frequency control method. At the same time, in order to further improve the control performance and reduce certain costs, in the continuous exploration of advanced control theory, the application of permanent magnet synchronous motor have been applied, which mainly in the following research directions: First, the control of the magnetic field, mainly including the magnetic field collection method and the asynchronous motor magnetic field acceleration method; Secondly, it is necessary to modulate the PWM with area method, graphic method, calculation method, and optimization method in principle. Thirdly, new power integration modules such as IGBTs and GTRs are widely used in the intelligent power devices; Fourthly, to realize the digitization of technologies, the hardware with artificial circuit develop into the direction of digital circuit with microprocessors as the core part ${ }^{[10]}$.

\section{Significance of researches on permanent magnet synchronous motor controller}

There is still a big gap between China's electrical machanical control technology and foreign countries. a number of universities and research institutes in China shall be established for the research and development of this technology so that China's motor control technology would make considerable progress. We propose a completely new digital solution for the variable-frequency speed control system of permanent magnet synchronous motor, and make it have practical significance and advanced nature. In addition to electric vehicle drive, it can also be used in AC drive systems, such as industrial sewing machines and robots, etc. ${ }^{[11]}$.

\section{Advantages and innovations of permanent magnet synchronous motor controller to other traditional control system}

After the traditional control system operates for a long period of time, it is easy to cause the aging of devices, and drifting because of environmental factors and other external factors. For rigorously-formulated parameters, instability of the control performance may be caused, and the change to the outside temperature is more sensitive, and the application of modern control thinking is more difficult. Due to the introduction of a new generation of SCM as the controller, in the application, the real-time requirements for control of high speed and high performance have been guaranteed, and the powerful event manager can handle system faults in a short time, at the same time, the monitoring signal drive power must be changed to the inverter unit, and the output and input of the monitoring signal should be protected ${ }^{[12]}$. The permanent magnet synchronous motor control system also has the real-time guarantee and can implement complex control algorithms. The innovation of this system is to introduce some advanced control theory algorithms into the specific quality control system, so that the entire quality control system has high torque response characteristics and advanced nature. The permanent magnet synchronous motor control system we studied can be widely applied, not only in the traction drive system of electric vehicles, but also in some industrial control fields, such as sewing machines and machine tools, and so on. Practice has proved that these the results of these applications are quite excellent. It should be noted that permanent magnet synchronous motor controllers have great market potential for applications in the field of industrial sewing machines. 


\section{Conclusion}

With the continuous development of our China's economy, the development speed of the automobile manufacturing industry is getting faster and faster. The application of permanent magnet synchronous motor has been very extensive, and achieved more ideal application effect, and the innovation in its controller has been realized in the new technology field. This paper analyzes the permanent magnet synchronous motor and its controller for electric vehicles, and expresses views of the author, and hoped to help the long-term stable development in the industry.

\section{Acknowledgements}

Fund Item:1) 2016 Science and Technology Research Program of Jiangxi Provincial Department of Education (Program No. GJJ161221), Program Name: Study on Key Control Technology of permanent magnet Synchronous Motor for Electric Vehicle; 2) 2017 Science and Technology Research Program of Jiangxi Provincial Department of Education (Program No. GJJ171100), Program Name: Study on Key Technology of Variable Speed Constant Frequency Doubly-fed Stand-alone Power System.

\section{References}

[1] Wang Huan. The Research of PMSM Design for Electric Vehicle [D]. Shenyang University of Technology, 2017.

[2] Yang Weihua. Research on Permanent Magnet Synchronous Motor and Its Controller in Electric Vehicle [D]. Hubei University of Technology, 2014.

[3] Bai Shan, Yu Songjian. Design and Analysis on Permanent Magnet Synchronous Motor for Modern Electric Vehicle [J]. Electric Age, 2016, 12 (12):58-60.

[4] Bing Liming. Research on Control Strategy of Permanent Magnet Synchronous Motor in Electric Vehicle [D]. Hubei University of Technology, 2013.

[5] Yu Yingchao. Flux-weakening Control for IPMSM of Electric Vehicles [D]. Qingdao University of Science \& Technology, 2017.

[6] Zhu Yuan, Wu Sibei, Wu Zhihong, Lu Ke. Precise Torque Control Method of IPMSM in Vehicle [J]. Transactions of the Chinese Society for Agricultural Machinery, 2014, 45(01):8-13.

[7] Guo Hao. Sensorless Vector Control System of Permanent Magnet Synchronous Motor Used in Electric Vehicle [D]. Qingdao University of Science \& Technology, 2017.

[8] Xu Jiaqun, Zhu Jianguang, Xing Wei, Tang Renyuan. Study of Efficiency Optimization Control of Permanent Magnet Synchronous Motor Drives for Electric Vehicle [J]. Transactions of China Electrotechnical Society, 2014, 12 (07):81-84+89.

[9] Zhang Yupeng. Research on the Flux-Weaken Speed Control System for Permanent Magnet Synchronous Motor for Electric Vehicle [D]. North China Electric Power University (Beijing), 2017.

[10] Xu Yanliang. Study on Power Capability and Flux-weakening Level of Permanent Magnet Synchronous Motor in Electric Vehicle Application (1) -- Power Capability When Constant Torque and Flux-weakening Control [J]. Journal of Shandong University (Engineering Science), 2015, 17(05):401-405.

[11] Zhou Xiangzhen, Zhang Shun. Research on Rotor Position Self-Sensing Control System of a PMSM for Electric Vehicles [J]. Micro motor, 2016, 44 (12):48-52+57.

[12] Xu Yanliang, Xu Jiaqun, Tang Renyuan. Study on Winding Switching of Permanent Magnet Synchronous Motor in EV Application [J]. Transactions of China Electrotechnical Society, 2014, 15 (05):21-25. 